\title{
Fabrication of Polyaniline Based Chemical Sensor for Ammonia Gas Detection
}

\author{
Roslinda Mustapa, Zakira Imana Abu Mansor and Kavirajaa Pandian Sambasevam* \\ School of Chemistry and Environment, Faculty of Applied Sciences, \\ Universiti Teknologi MARA, Negeri Sembilan Branch, Kuala Pilah Campus, \\ 72000 Kuala Pilah, Negeri Sembilan, Malaysia \\ *Corresponding author: kavirajaa@live.com
}

Published online: 25 February 2018

To cite this article: Mustapa, R., Abu Mansor, Z. I. \& Sambasevam, K. P. (2018). Fabrication of polyaniline based chemical sensor for ammonia gas detection. J. Phys. Sci., 29(Supp. 1), 9-16, https://doi.org/10.21315/jps2018.29.s1.2

To link to this article: https://doi.org/10.21315/jps2018.29.s1.2

\begin{abstract}
Polyaniline (PAni) is one of the versatile conducting polymers due to inexpensive monomer, environmental benign, high conductivity and easy preparation. In this study, PAni was doped by dioctyl sulfosuccinate sodium (AOT) to enhance the processability of PAni in gas sensor detection. PAni/AOT was synthesised via in-situ polymerisation at $0^{\circ} \mathrm{C}$ for $24 \mathrm{~h}$ in the presence of potassium peroxydisulfate (KPS). The characterisations were done by Fourier transform infrared (FTIR) and ultravioletvisible (UV-Vis). FTIR spectra depict the main characteristic peaks of PAni/AOT at $1550 \mathrm{~cm}^{-1}$ and $1455 \mathrm{~cm}^{-1}$ which indicates quinoid and benzoid units, respectively. The presence of AOT dopant was confirmed by observing the peak at $1731 \mathrm{~cm}^{-1}$. UV-Vis spectra further confirmed the PAni/AOT is in the doped state by exhibiting a characteristic peak at $\sim 800 \mathrm{~nm}$. Sensor performance of PAni/AOT film was studied in terms of selectivity, long term stability and method validation. It was found that, PAni/AOT exhibited stability up to 1 week. Besides that, PAni/AOT film also exhibited good selectivity for $\mathrm{NH}_{3}$ in the presence of common interfering species such as hexane, diethyl ether and acetone gas. In conclusion, PAni/AOT was successfully prepared for $\mathrm{NH}_{3}$ detection. The limit of detection of PAni/AOT was 11 ppm.
\end{abstract}

Keywords: Conducting polymer, semiconductor, potassium persulphate, sensor, toxic gas 


\section{INTRODUCTION}

Ammonia $\left(\mathrm{NH}_{3}\right)$ has been identified as a toxic compound with its atmospheric threshold value of $25 \mathrm{ppm} .{ }^{1}$ It can cause irritation when inhaled or contacted on skin and eyes. At high concentration, it can cause temporary blindness and severe injury to mucous membrane ${ }^{2}$ Conducting polymer is a material that exhibits the characteristic of a metal while preserving the characteristic of a polymer. Conductive polymer has been recently used as one of the effective sensor. Amongst all of the conductive polymers, polyaniline (PAni) is one of the most promising polymer to be cultivated in gas sensor study. PAni can exhibit various oxidation state such as emeraldine salt, emeraldine base, pernigraniline and leucomeraldine. Interaction of $\mathrm{NH}_{3}$ with PAni can alternate the properties of PAni in term of its oxidation state. A study on PAni/ESP blend has shown to have successful application on $\mathrm{NH}_{3}$ sensing. ${ }^{3}$ This is due to its stability, low cost and ease of synthesis. ${ }^{2}$ However, the PAni has low mechanical strength and processing ability that hinders its performance as a gas sensor. ${ }^{4}$ Therefore, in order to improve its processability, doping of PAni with suitable surfactant is commonly used. Up to date, various surfactants have been utilised such as camphorsulfonic acid (CSA), sodium dodecyl sulfate (SDS) and dodecylbenzenesulphonic acid (DBSA). ${ }^{2}$

The objective of this study is to manipulate PAni/AOT as a conducting polymer which will be applied as an $\mathrm{NH}_{3}$ sensor. The PAni will be synthesised by using chemical oxidation method and doped with dioctyl sulfosuccinate sodium (AOT). The characterisation of PAni/AOT was analysed using ultraviolet-visible (UV-Vis) and Fourier transform infrared (FTIR).The PAni/AOT sensor performance was evaluated using multimeter.

\section{EXPERIMENTAL}

\subsection{Material}

Aniline (Ani) was purchased from Merck. Ammonia $\left(\mathrm{NH}_{3}\right)$ and potassium peroxudisulfate (KPS) were purchased from QReC and $\mathrm{HmbG}$, respectively. Hydrochloric acid $(\mathrm{HCl})$ and toluene were purchased from R\&M Chemical. AOT was provided by University of Malaya, Malaysia. Toluene was used as solvent for PAni/AOT. Distilled water was used throughout this experiment.

\subsection{Synthesis of PAni/AOT Film}

The synthesis was done at $0^{\circ} \mathrm{C}$ for $24 \mathrm{~h}$ using an in-situ polymerisation technique. An amount of $7 \mathrm{mmol}$ of AOT was dissolved in $1 \mathrm{M} \mathrm{of} \mathrm{HCl}$ and stirred for $1 \mathrm{~h}$. 
An amount of $5 \mathrm{mmol}$ of Ani was then added dropwise and stirred for $1 \mathrm{~h}$. After that, $5 \mathrm{mmol}$ of pre-cooled KPS was added dropwise for $1 \mathrm{~h}$. The mixture was left stirred for $24 \mathrm{~h}$ to allow polymerisation. After $24 \mathrm{~h}$, the PAni precipitate was filtered and washed several times using distilled water. The PAni precipitate was dissolved in toluene. ${ }^{2}$ The solution was casted on a glass slide using spin coating technique. The spin-coated PAni film was used as a gas sensor in $\mathrm{NH}_{3}$ detection.

\subsection{Characterisation of PAni/AOT}

PAni/AOT film was characterised by using FTIR Perkin Elmer model FTIR spectrum 100 spectrometer in the range of $650-4000 \mathrm{~cm}^{-1}$ and PG instrument T80/T80+ ultraviolet-visible (UV-Vis) in the range of 300-900 $\mathrm{nm}$.

\subsection{Sensor Performances of PAni/AOT Film}

The sensitivity of PAni/AOT film was calculated using equation $\% \mathrm{~S}=\left[\left(\mathrm{R}_{\mathrm{f}}-\mathrm{R}_{\mathrm{i}}\right) / \mathrm{R}_{\mathrm{i}}\right]$ $\times 100 \%$ where, $R_{i}=$ intial resistance and $R_{f}=$ final resistance. ${ }^{5}$ The long term stability was studied by performing sensitivity test of the PAni film each day for up to 1 week. ${ }^{2}$ The sensitivity of sensor was observed by using multimeter. The selectivity study was done by exposure of PAni/AOT film with other gases such as acetone, diethyl ether and hexane. ${ }^{5}$

\section{RESULTS AND DISCUSSION}

\subsection{Characterisation of PAni/AOT Film}

The characterisation for PAni/AOT was done by FTIR and UV-Vis spectrometers. Figure 1 depicts FTIR spectrum of PAni/AOT that recorded in the range of $650-4000 \mathrm{~cm}^{-1}$. The bands at $1235 \mathrm{~cm}^{-1}$ and $1290 \mathrm{~cm}^{-1}$ were attributed to the $\mathrm{C}-\mathrm{N}+$ stretching vibration of polaron structure and delocalisation of $\pi$ electrons along the PAni backbone, respectively. ${ }^{2}$ The presence of emeraldine salt state of PAni/AOT was confirmed by the bands at $1455 \mathrm{~cm}^{-1}$ and $1550 \mathrm{~cm}^{-1}$ that corresponds to the stretching vibration of $\mathrm{C}=\mathrm{N}$ and $\mathrm{C}=\mathrm{C}$ at the quinoid site and stretching vibration of $\mathrm{C}-\mathrm{C}$ benzenoids in the PAni structure. ${ }^{4}$ The AOT dopant structure confirmed by $\mathrm{C}=\mathrm{O}$ and $\mathrm{S}=\mathrm{O}$ symmetry at $1731 \mathrm{~cm}^{-1}$ and $1178 \mathrm{~cm}^{-1}$, respectively. ${ }^{2}$ The band at $3238 \mathrm{~cm}^{-1}$ and $3158 \mathrm{~cm}^{-1}$ attributed to $\mathrm{C}-\mathrm{H}$ and N-H at PAni backbone. ${ }^{4}$ The $\mathrm{O}-\mathrm{H}$ arises at $3448 \mathrm{~cm}^{-1}$ due to impurities.

Figure 2 shows UV-Vis absorption spectrum of PAni/AOT in the range of 300-900 nm. The spectrum exhibits three distinctive peaks at $\sim 360 \mathrm{~nm}, \sim 420 \mathrm{~nm}$ and $\sim 790 \mathrm{~nm}$. The peak at $\sim 360 \mathrm{~nm}$ indicates the $\pi-\pi^{*}$ conjugation of benzenoid 
structure. The shoulder peak at $\sim 420 \mathrm{~nm}$ attributed to the polaronic character while the peak at $\sim 790 \mathrm{~nm}$ contributes to the $\pi$-polaron that showed the doped state of quinoid cation. ${ }^{2,4}$ Thus, FTIR and UV-Vis spectra confirms the PAni/AOT present in the conducting state which is better known as emeraldine salt.

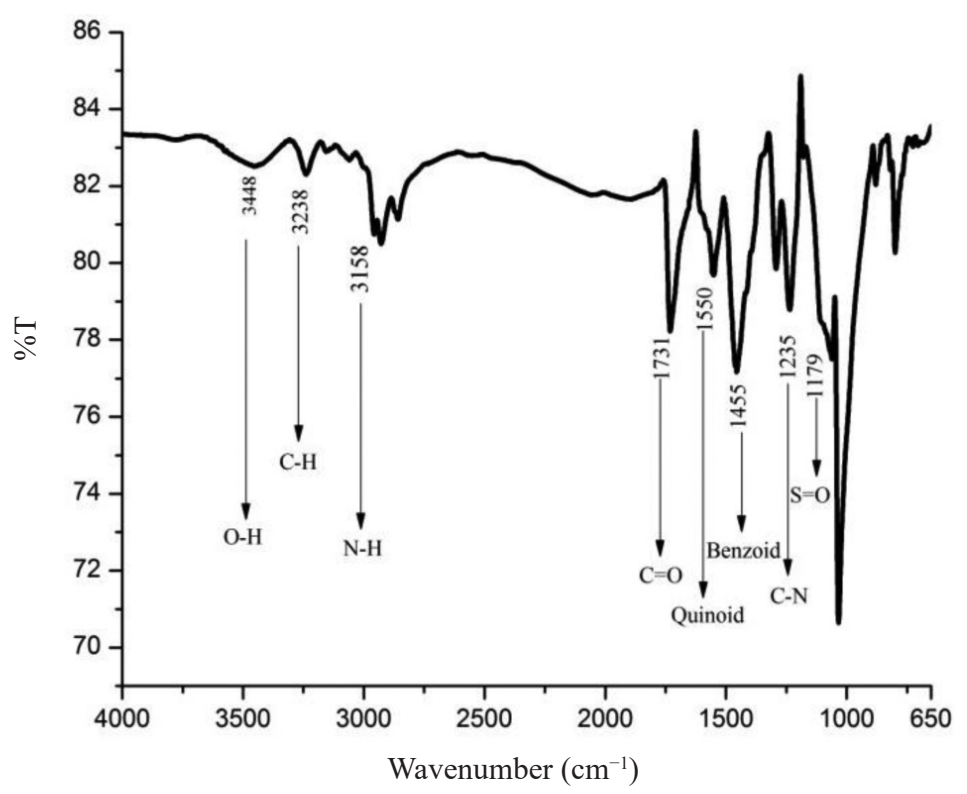

Figure 1: FTIR spectrum of PAni/AOT.

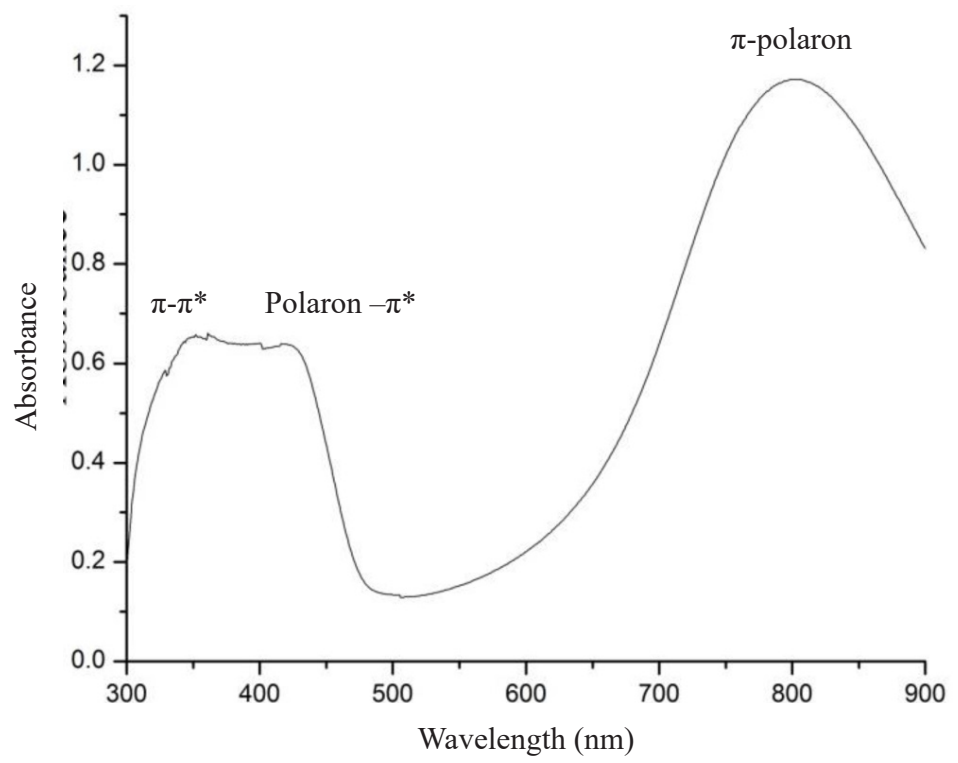

Figure 2: UV-Vis spectra of PAni/AOT. 


\subsection{Sensor Performances}

\subsubsection{Selectivity of PAni/AOT film}

The selectivity study was conducted by testing the PAni/AOT sensor in different target gases such as $\mathrm{NH}_{3}$, acetone, diethyl ether and hexane at similar concentration. The PAni/AOT sensor showed high selectivity toward $\mathrm{NH}_{3}$ as shown in Figure 3 compare to other gases. Based on the hydrophilic nature of PAni/AOT, the higher the polarity of vapour gas, the higher the interaction of PAni/AOT chains with vapour gases. ${ }^{6}$ PAni/AOT is more selective toward $\mathrm{NH}_{3}$ due to the interaction of PAni/AOT with $\mathrm{NH}_{3}$ is ion-dipole while interaction of PAni/AOT with other gases are dipole-induced dipole interaction. Dipole-induced dipole interaction is weaker compared to ion-dipole interaction. ${ }^{5}$

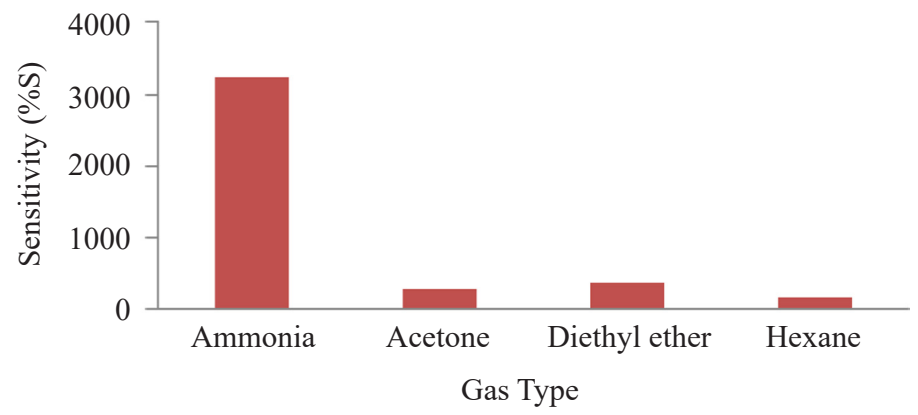

Figure 3: The selectivity of PAni/AOT film towards different vapor gases.

\subsubsection{Long-term stability study of PAni/AOT film}

The long-term stability study of PAni/AOT film in $\mathrm{NH}_{3}$ was studied for one week and shown in Figure 4. PAni/AOT shows good sensor response $(>90 \% \mathrm{~S})$ for 1 week. ${ }^{5}$ However, the PAni/AOT's sensor sensitivity decreases after one week due to humidity. ${ }^{7}$ Figure 4 also displays that PAni/AOT can be reused up to 7 days. The improper storage of PAni/AOT film would lead to an interaction with ambient air that causes degradation of the film as well. ${ }^{7}$

\subsubsection{Method validation}

Figure 5 shows calibration plot of sensitivity against different concentrations of ammonia. The linear line segment has linear equation of $y=5.2743 x-186.4$ with correlation coefficient of 0.9812 . Limit of detection (LOD) was calculated by using STYEX method. ${ }^{8}$ The LOD was calculated using Equation 1:

$$
\text { LOD }=3.3 \frac{\text { STYEX }}{\text { SLOPE }}
$$


The LOD obtained for PAni/AOT was $\sim 11 \mathrm{ppm}$. The LOD of PAni/AOT was reliable because it is lower compared to $\mathrm{NH}_{3}$ threshold value. Besides, PAni/ AOT film shows high sensitivity compared to reported articles and lower than the threshold value of $\mathrm{NH}_{3} \cdot{ }^{9,10}$ Moreover, PAni/AOT was easy to synthesise, inexpensive and easy to setup.

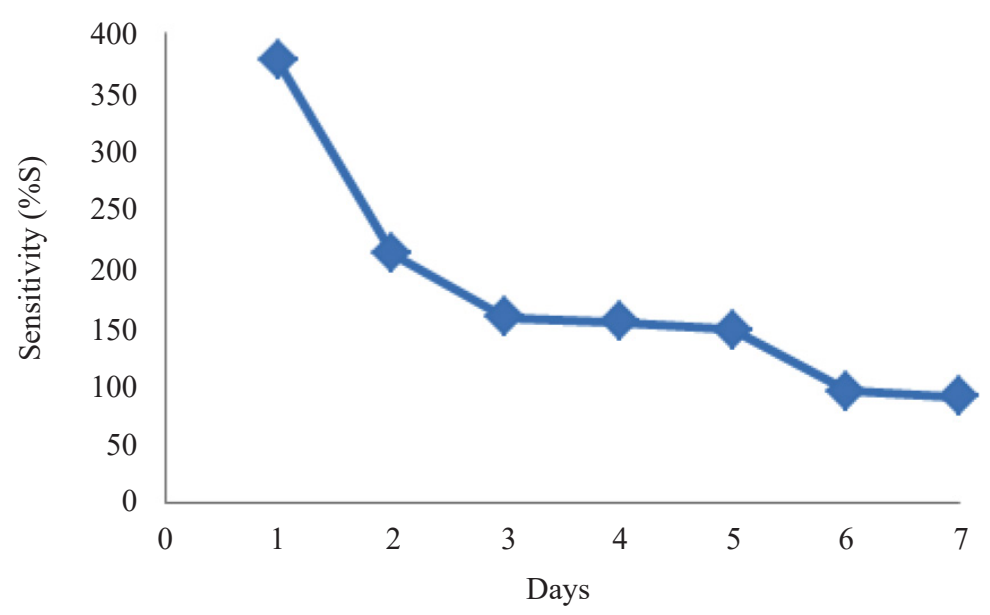

Figure 4: Long-term stability of PAni/AOT film.

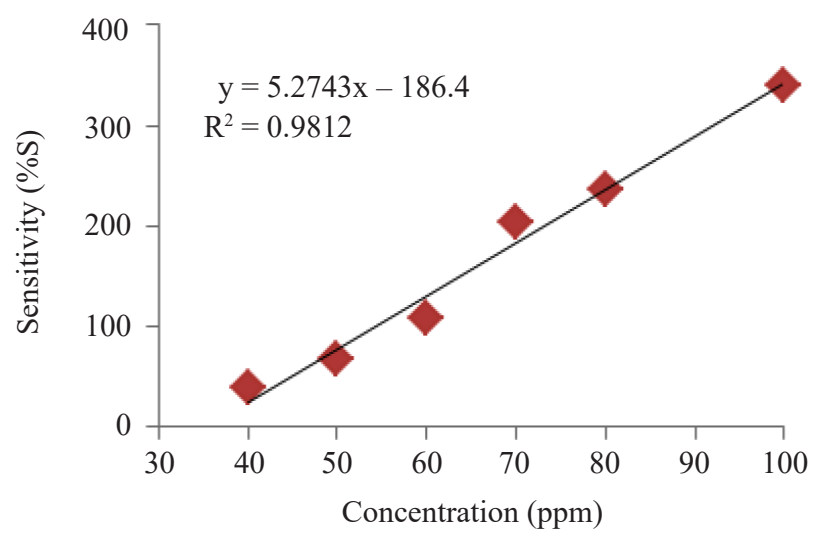

Figure 5: Calibration plot of PAni/AOT film.

\section{CONCLUSION}

As a conclusion, the PAni/AOT was successfully synthesised and applied effectively in $\mathrm{NH}_{3}$ detection. The PAni/AOT film exhibited good sensor performances in terms of long term stability and selectivity. Besides, PAni/AOT film also reported 
good LOD of $\sim 11 \mathrm{ppm}$ in comparison with other PAni sensors in the literature. Therefore, it has been proven that the use of AOT as a surfactant to improve the processability of PAni in sensor application is most welcomed and future studies will be directed towards comparing PAni/AOT with other PAni/surfactants.

\section{ACKNOWLEDGEMENTS}

The authors would like to show gratitude to Universiti Teknologi MARA (UiTM) for financial support to attend International Conference for Young Chemists (ICYC2017) and University of Malaya for chemical support.

\section{REFERENCES}

1. US Department of Health and Human Services. (1992). Occupational safety and health guideline for ammonia. New York: US Department of Health and Human Services, https://doi.org/10.1016/j.mssp.2015.01.008.

2. Sambasevam, K. P., Mohamad, S. \& Phang, S. W. (2015). Effect of dopant concentration on polyaniline for hydrazine detection. Mater. Sci. Semicon. Process., 33, 24-31.

3. Ghani, S. A., Zakaria, A. \& Shakaff, A. Y. (2012). Enhancing conductive polymer performance using eggshell for ammonia sensor. J. Phys. Sci., 23(2), 73-83.

4. Sambasevam, K. P., Mohamad, S. \& Phang, S. W. (2015). Enhancement of polyaniline properties by different polymerization temperatures in hydrazine detection. J. Appl. Polym. Sci., 132(13), 1-8, https://doi.org/10.1002/ app.41746.

5. Kumar, L. et al. (2017). Flexible room temperature ammonia sensor based on polyaniline. Sens. Actuat. B Chem., 240, 408-416, https://doi.org/10.1016/j. snb.2016.08.173.

6. Gao, J. (2003). Tunable polyaniline chemical actuators. Chem. Mater., (14), 2411-2418, https://doi.org/10.1021/cm020329e.

7. Li, Y., Deng, C. \& Yang, M. (2012). A novel surface acoustic waveimpedance humidity sensor based on the composite of polyaniline and poly (vinyl alcohol) with a capability of detecting low humidity. Sens. Actuat. B Chem., 165(1), 7-12, https://doi.org/10.1016/j.snb.2011.12.037.

8. Jokar, M., Safaralizadeh, M. H. \& Hadizadeh, F. (2015). Design and evaluation of an apta-nano-sensor to detect acetamiprid in vitro and in silico. J. Biomol. Struct. Dynam., 1102, 1-26. 
9. Menegazzo, N. et al. (2011). Discourse on the utilization of polyaniline coatings for surface plasmon resonance sensing of ammonia vapor. Talanta, 85, 1369-1375, https://doi.org/10.1016/j.talanta.2011.06.020.

10. Andre, R. S. et al. (2017). Hybrid layer-by-layer (LbL) films of polyaniline, graphene oxide and zinc oxide to detect ammonia. Sens. Actuat. B Chem., 238, 795-801, https://doi.org/10.1016/j.snb.2016.07.099. 